\title{
An eco-friendly method for extraction and determination of ciprofloxacin in blood serum and pharmaceuticals
}

\author{
Zuhair Abdul Al-Ameer Khammas", Noora Saad Mubdir \\ Department of Chemistry, College of Science for Women, University of Baghdad, Jadiyriah, Baghdad, Iraq \\ Email address: \\ dr_zuhair52@yahoo.com (Z.A-A Khammas), noorasaad_81@yahoo.com (N. S. Mubdir)
}

To cite this article:

Zuhair A-A Khammas, Noora S. Mubdir. An Eco-Friendly Method for Extraction and Determination of Ciprofloxacin in Blood Serum and Pharmaceuticals. Science Journal of Analytical Chemistry. Vol. 2, No. 5, 2014, pp. 47-54. doi: 10.11648/j.sjac.20140205.11

\begin{abstract}
A method was established for the determination of ciprofloxacin hydrochloride (CIPRO) in the blood serum and pharmaceutical samples by a combination of cloud point extraction with UV-Vis spectrophotometry. The method included the formation of $\mathrm{Fe}$ (III) - CIPRO complex in presence of dilute $\mathrm{H}_{2} \mathrm{SO}_{4}$, followed the extraction of the complex by cloud point extraction using non-ionic surfactant Triton X-114. The surfactant phase extracted was dissolved in little amount of solvent and the CIPRO quantity measured spectrophotometerically at absorption maximum of $437 \mathrm{~nm}$. The effect of the experimental factors which affect the CPE efficiency was optimized by classical method. The preconcentration and enrichment factors were found to be 40 and 143 fold respectively, achieving the detection limit of $0.77 \mu \mathrm{gL}^{-1}$ and linear range of $2.5-120 \mu \mathrm{g} \mathrm{mL} L^{-1}$ with correlation coefficient of 0.9984 , under the optimum conditions. The average recovery percentage of CIPRO was of $98.89 \pm 0.87 \%$ and the precision in the range of $1.15-2.85 \%$. The suggested method was applied for the determination of CIPRO in the serum samples of different subjects orally administrated for two hours with Emicipro 500, in addition to drug formulations like UFEXIL $^{\circledR}$ infusion and Ciprodar ${ }^{\circledR}$ tablets. The experimental values were agreed with the quoted values that stated by the manufacturer' companies.
\end{abstract}

Keywords: Ciprofloxacin HCl, Ferric Ion, Cloud Pint Extraction, Spectrophotometry

\section{Introduction}<smiles>O=C(O)c1cn(C2CC2)c2cc(N3CCNCC3)c(F)cc2c1=O</smiles>

Figure 1. The Chemical structure of ciprofloxacin $\left(\mathrm{C}_{17} \mathrm{H}_{18} \mathrm{FN}_{3} \mathrm{O}_{3} . \mathrm{HCl}, \mathrm{M} . \mathrm{W}\right.$. $367.80 \mathrm{~g} / \mathrm{mol})[1]$.

Ciprofloxacin hydrochloride (abbreviated as CIPRO) acts as antibacterial agent is chemically described as (1-cyclopropyl-6-fluoro-4-oxo-7-(piperazin-1-yl)-quinoline-3 -carboxylic acid, monohydrochloride monohydrate, Fig.1)[1]. It is a second-generation fluoroquinolone antibiotic that used clinically in the late 1980s and early 1990s [2-3]. It is widely used antibiotics due to its broad spectrum drug of activity against common aerobic Gram-negative and Gram-positive bacterial pathogens to combat infections caused by micro-organisms that are resistant or multi-resistant to other antimicrobials, such as amino glycosides, tetracyclines or $\beta$-lactam[4] . CIPRO is commonly used to treat a wide variety of infections such as common urinary tract, certain gastrointestinal infections, gynaecological infections/STDs, skin infections, respiratory tract infections(such as sinusitis, pneumonia, bronchitis ), prostatitis, anthrax and chancroid [5].

The chemical literature survey revealed that the most methods for detection of ciprofloxacin in tablets and injection formulations include, electroanalytical methods [6-7], high performance liquid chromatography (HPLC [8-15], high performance liquid chromatography- mass spectrometry (HPLC-MS) [16], capillary electrophoresis [17], spectrofluorimetry [18] and spectrophotometry [19-23]. However, there are a limited number of published papers for the determination of CIPRO in biological specimens by high performance liquid chromatography in which either use ultraviolet (UV) or fluorescence detections [24-30]. Although these techniques are sophisticated and have a high detection power, but they are relatively expensive, not commonly available in all laboratories, need an internal standard and some involve more than one extraction step. In contrast, ultraviolet-visible (UV-Vis) spectrophotometry is a simple 
instrument, cheap, easy operated, rapid response time, available in many laboratories and provides acceptable analytical figures of merit in determining organic compounds in different matrices [31]. However, due to its poor detection power, the extraction and preconcentration procedures are necessary to improve the detection limit as well as the selectivity of the technique [31]. Recently, the combination of UV-Vis spectrophotometry with cloud point extraction (CPE) has offered a promising alternative method of improving conventional analytical procedure toward easy, simple and inexpensive routine analyses of organic and inorganic analytes in different matrices instead of using expensive instrumentations [32-33]. The separation/preconcentration of medicaments employing CPE, especially in biological, environmental and forensic matrices has not received much attention so far [34]. However, few reports have appeared in the chemical literatures reflect the application merit of $\mathrm{CPE}$ coupled with instrumentation for drugs extraction and enrichment, for example, phenothiazine by CPE- gas chromatography in spiked human serum [35], thiamine using CPE-spectrofluorimetric method in urine samples [36] terazosin by cloud point extraction-fluorimetric in biological fluids [37], meloxicam by CPE-high-performance liquid chromatography in human serum [38], ofloxacin and gatifloxacin by using CPE-fluorimetry in biological fluids and pharmaceuticals [39].

In this research work, a new method was developed for the detection of ciprofloxacin hydrochloride in human serum and pharmaceuticals samples by coupling CPE with UV-Vis spectrophotometry. The method relies on the formation of complex between CIPRO and Fe (III) in the presence of dilute $\mathrm{H}_{2} \mathrm{SO}_{4}$, followed the extraction of the complex by cloud point extraction using Triton X-114 at the optimum established conditions. The extracted phase was dissolved in a little amount of ethanol and CIPRO determined by UV-Vis spectromphotometry at $\lambda_{\max }$ of $437 \mathrm{~nm}$. The proposed method was applied for the determination of CIPRO in blood serum for some volunteers and drug formulations samples.

\section{Materials and Methods}

\subsection{Apparatus}

The scanning of the absorption spectra and absorbance measurements of the analytes under study were conducted by employing a Shimadzu double-beam UV-Vis Spectrophotometer model UV-1800 (Kyoto, Japan) equipped with $10-\mathrm{mm}$ optical path cell. Thermostatic water bath (WNB7-45) Experts (England) was used for CPE experiments. For solution $\mathrm{pH}$ measurements a portable $\mathrm{pH}$-meter microprocessor (HANNA, Germany) was used.

\subsection{Reagents and Materials}

Distilled water and chemicals used in this work are of analytical reagent grade. Triton X-114 (average molecular weight of $537 \mathrm{~g} / \mathrm{mol}$ ), was obtained from ACROSORGANICS (New Jersey, USA) .The aqueous solution $(10 \% \mathrm{v} / \mathrm{v})$ of Triton X-114 was prepared by diluting $10 \mathrm{~mL}$ of concentrated solution in $100 \mathrm{~mL}$ water. A pure grade ciprofloxacin-HCl (CIPRO) was supplied by the Drug Industries and Midical Appliance (SID) Samarra/ Iraq. A stock solutions of $1000 \mu \mathrm{g} \mathrm{mL} \mathrm{m}^{-1}$ for ciprofloxacin hydrochloride were prepared by dissolving $100 \mathrm{mg}$ in $100 \mathrm{~mL}$ distilled water and the working solutions were daily prepared by appropriate dilutions in pure water. A stock solutions of $\mathrm{Fe}^{3+}\left(1000 \mathrm{mg} \mathrm{L}^{-1}\right)$ was prepared by dissolving $0.8634 \mathrm{~g}$ of pre-dried ammonium ferric sulfate $(\mathrm{BDH})$ in $0.050 \mathrm{M}$ sulfuric acid (BDH) in $100 \mathrm{~mL}$ volumetric flask. This solution is only used after at least $24 \mathrm{~h}$ to guarantee complete dissolution. Ethanol was purchased from (Abo Teeba). A 0.1 M sulphuric acid (1M) solution was prepared by diluted $5.43 \mathrm{~mL}$ of $98 \% \mathrm{H}_{2} \mathrm{SO}_{4}(1.84 \mathrm{~g} / \mathrm{mL}, \mathrm{BDH})$ with distilled water in $1 \mathrm{~L}$ calibrated flask.

\subsection{General Procedure for $C P E$}

In a $10 \mathrm{~mL}$ volumetric flask, an amount of ciprofloxacin standard or sample solution matched within calibration range, $0.6 \mathrm{~mL}$ ferric ion solution $\left(100 \mu \mathrm{g} \mathrm{mL} \mathrm{m}^{-1}\right), 0.5 \mathrm{~mL}$ of $\mathrm{H}_{2} \mathrm{SO}_{4}$ $\left(1 \times 10^{-4} \mathrm{M}\right)$ and $1 \%$ Triton $\mathrm{X}-114(1 \% \mathrm{v} / \mathrm{v})$ were added ,mixed and dilute with to mark with water. Afterwards the content of the flask was transferred into $10 \mathrm{~mL}$ centrifuging tube and then kept for $25 \mathrm{~min}$ in the thermostatic bath at $75{ }^{\circ} \mathrm{C}$. The separation of the phases was carried out by centrifugation at $6000 \mathrm{rpm}$ for $20 \mathrm{~min}$. The phases were cooled down in an ice bath in order to increase the viscosity of the surfactant-rich phase. The surfactant-poor phase was easily poured by inverting the tube. The surfactant-rich phase that contains the complex was dissolved with suitable amount with ethanol and the absorbance of the complex measured at $437 \mathrm{~nm}$ against a reagent blank prepared under similar conditions.

\subsection{Preparation of Serum Samples}

In an attempt to detect the ciprofloxacin in the real serum sample, ten adult volunteers were randomly designated to take orally a single tablet of Emicipro ${ }^{\circledR} 500$ (Globalpharma Co. L.L.C. Dubai, UAE) containing $500 \mathrm{mg}$ ciprofloxacin. None of the volunteers was ill or taking any medication at the time of this administration. After two hours of administration, blood sample $(5 \mathrm{~mL})$ were withdrawn from the vein of each subject by using medical syringe and then transferred immediately into centrifuging tubes. The content of each tube was centrifuged for $15 \mathrm{~min}$ to separate the serum from the whole blood and all serum samples were kept freeze in refrigerator until analysis [40]. The serum samples were thawed at ambient temperature. A $0.2 \mathrm{~mL}$ of each serum sample was taken and subjected to the recommended CPE procedure and then the CIPRO content was quantified spectrophotometry at $\lambda_{\max }$ of $437 \mathrm{~nm}$. For the purpose of comparison, CIPRO content in each serum sample was directly determined after appropriate dilution by traditional $\mathrm{UV}$-Vis spectrophotometry at $\lambda_{\max }$ of $271 \mathrm{~nm}$.

\subsection{Sample Preparation of Drugs}

Two types of pharmaceuticals were chosen for the 
determination of CIPRO content by the proposed method. These are; Ciprofloxacin $200 \mathrm{mg} / 100 \mathrm{~mL}$ solution for infusion bottles type UFEXIL ${ }^{\circledR}$ (Manufactured by DEM O S.A. Pharmaceutical industry, Greece) and Ciprodar ${ }^{\circledR}$ of $0.3 \%$ eye drop (Manufactured by Dar Al Dawa, Na' and ur-Jordan). Simply, each sample was analyzed after a suitable dilution with distilled water followed the general CPE procedure and CIPRO content was determined spectrophotometrically at $\lambda_{\max }$ of $437 \mathrm{~nm}$.

\subsection{Statistical Analysis}

Excel 2007 (Microsoft Office $^{\circledR}$ ) and Minitab version 14 (Minitab Inc., State College, PA, USA) were employed to carry out all statistical calculations such as regression and correlation analysis, ANOVA and significance tests.

\section{Results and Discussion}

\subsection{Absorption Spectra}

The absorption spectra of ferric ion solution, CIPRO solution and $\mathrm{Fe}$ (III)-CIPRO complex in dilute $\mathrm{H}_{2} \mathrm{SO}_{4}$ and in the presence of Triton X-114 against blank solution were recorded between 190 and $600 \mathrm{~nm}$ by a Shimadzu UV1800 equipped with $10-\mathrm{mm}$ quartz cell. Figure 2 shows that the absorption maximum of Fe (III)-CIPRO complex occurs in visible region with shoulder peak at $\lambda_{\max }$ of $437 \mathrm{~nm}$, while ciprofloxacin drug displays two maxima at 271 and $330 \mathrm{~nm}$ and $\mathrm{Fe}$ (III) ion solution gave one distinct absorption band at $300 \mathrm{~nm}$. Thus the wavelength maximum of $437 \mathrm{~nm}$ for the complex was adopted throughout this study.

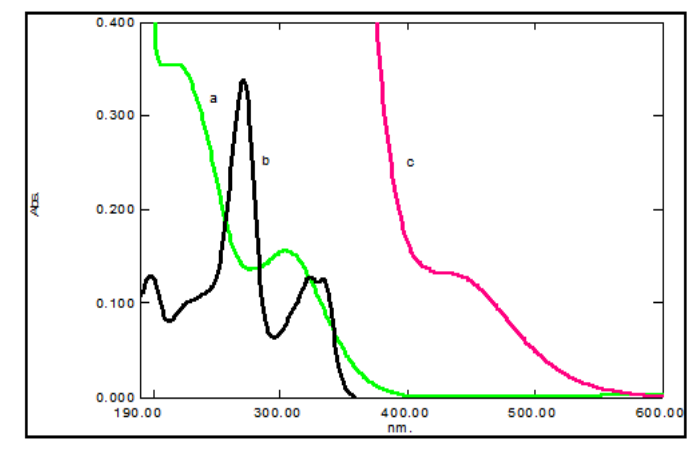

Figure 2. Absorption spectra (a) Fe (III) (b) Reagent Ciprofloxacin (c) $\mathrm{Fe}$-CIPRO complex.

\subsection{Optimization of CPE Procedure}

All the important factors may affect the CPE efficiency of the drug CIPRO were sequentially investigated by the classical optimization via changing one factor while keeping other factors constant. In this respect, the effect of $\mathrm{H}_{2} \mathrm{SO}_{4}$, concentration of ferric ion solution, non-ionic surfactant Triton X-114 amount, and equilibration temperature and incubation time were studied.

\subsubsection{Effect of $\mathrm{H}_{2} \mathrm{SO}_{4}$ Concentration}

It was reported that the concentration of $\mathrm{H}_{2} \mathrm{SO}_{4}$ plays an important role in the complexation reaction between ferric ion and CIPRO drug and it is responsible for the stoichiometric ratio of the complexation [41]. Accordingly, the effect of $\mathrm{H}_{2} \mathrm{SO}_{4}$ concentration on formation of the Fe-CIPRO complex in Triton X-114 medium was considered by recording the absorbance of the complex at $\lambda_{\max }$, over the range of $1 \times 10^{-2}$ $-1 \times 10^{-4} \mathrm{M} \mathrm{H}_{2} \mathrm{SO}_{4}$, while keeping Fe (III), CIPRO and Triton $\mathrm{X}-114$ at $6 \mu \mathrm{g} \mathrm{mL}^{-1}, 60 \mu \mathrm{g} \mathrm{mL} \mathrm{m}^{-1}$ and $1 \%$ (v/v) respectively. The results are shown in Figure 3. As can be seen in Figure 3, the absorbance at first increased with increasing $\mathrm{H}_{2} \mathrm{SO}_{4}$ concentration and reached a maximum at $5 \times 10^{-4} \mathrm{M} \mathrm{H}_{2} \mathrm{SO}_{4}$ and suddenly decreases thereafter. The decrease in absorbance at high concentration of acid may be attributed to the dissociation of complex and incomplete extraction in micelle.

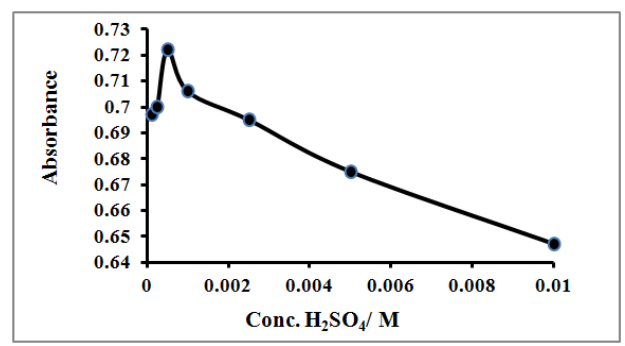

Figure 3. Effect of $\mathrm{H}_{2} \mathrm{SO}_{4}$ concentration on the formation of $\mathrm{Fe}$ (III) CIPRO complex by $C P E$.

Consequently, a concentration of $5 \times 10^{-4} \mathrm{M} \mathrm{H}_{2} \mathrm{SO}_{4}$ which corresponds to ionic strength of $1.5 \times 10^{-3} \mathrm{M}$ was selected as the optimal for complete formation of Fe (III)-CIPRO complex.

\subsubsection{Effect of Fe (III) Concentration}

The effect of the ferric ion concentration was studied by measuring the absorbance according to the general CPE procedure for the solution containing $60 \mu \mathrm{g} \mathrm{mL} \mathrm{m}^{-1}$ CIPRO, $5 \times 10^{-4} \mathrm{M} \mathrm{H}_{2} \mathrm{SO}_{4}, 1 \%$ (v/v) of Triton $\mathrm{X}-114$ and varying concentration of the $\mathrm{Fe}(\mathrm{III})$ solution ranged from 0.5-12 $\mu \mathrm{g}$ $\mathrm{mL}^{-1}$. It was shown that the analytical response increase rapidly as the concentration of $\mathrm{Fe}(\mathrm{III})$ ion increases and reach a maximum at $6 \mu \mathrm{g} \mathrm{mL}^{-1}$, indicating the complete formation of Fe(III)-CIPRO complex with a high extraction efficiency in the micelles medium. Thereafter, the absorbance decrease slightly with further increase in metal ion (Figure 4).Consequently, $6 \mu \mathrm{g} \mathrm{mL} \mathrm{m}^{-1}$ of Fe (III) was found to be enough for the complex formation from which it was used as optimum throughout this study.

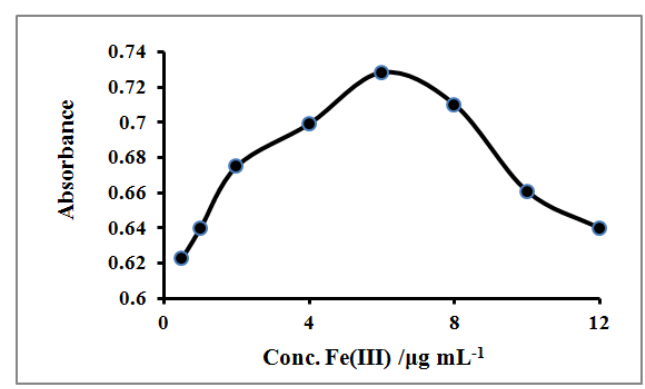

Figure 4. Effect of iron (III) concentration on the formation of Fe-CIPRO complex by $C P E$ 


\subsubsection{Effect of TritonX-114 Amount}

The influence of surfactant amount as an extracting medium is very significant to maximize the extraction efficiency by minimizing the phase volume ratio $(\mathrm{Vs} / \mathrm{Va})$, thus improving its concentration ability [42]. Therefore, the effect of the Triton $\mathrm{X}-114$ concentration on the absorbance of the extracted phase was studied within the surfactant volume range of $0.1-2 \mathrm{~mL}$ of $10 \%(\mathrm{v} / \mathrm{v})$. As shown in Fig. 5, the absorbance of the complex increased by increasing the Triton X-114 concentration up to $1.0 \mathrm{~mL}$ of $10 \%(\mathrm{v} / \mathrm{v})$ and then markedly decreased at higher amounts. At low amount of Triton X-114, low extraction efficiency occurs due to the inadequacy of the assemblies to entrap the hydrophobic complex quantitatively, while at higher amount led to deteriorate the detection signal and thus inefficient extraction. Therefore, a $1.0 \mathrm{~mL}$ of $10 \%(\mathrm{v} / \mathrm{v})$ Triton $\mathrm{X}-114$ was used as the optimum amount.

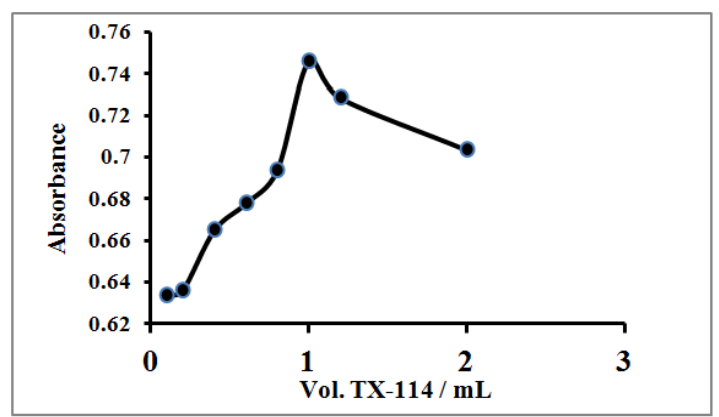

Figure 5. Effect of Triton X-114 amount on absorbance of Fe (III)-CIPRO complex

\subsubsection{Effect of Temperature and Time}

Figure 6 shows the effect of equilibration temperature on the absorption signal of the Fe (III)-CIPRO complex by varying temperature from 25 to $85^{\circ} \mathrm{C}$ at incubation time of 25 min. The experimental results have shown that the maximum absorbance signal for the Fe (III)-CIPRO complex was achieved at $75^{\circ} \mathrm{C}$. Thereafter, the CPE efficiency of the target complex decreases with increases of temperature. So, the temperature of $75^{\circ} \mathrm{C}$ was selected as optimal for maximum extraction of $\mathrm{Fe}$ (III)-CIPRO complex.

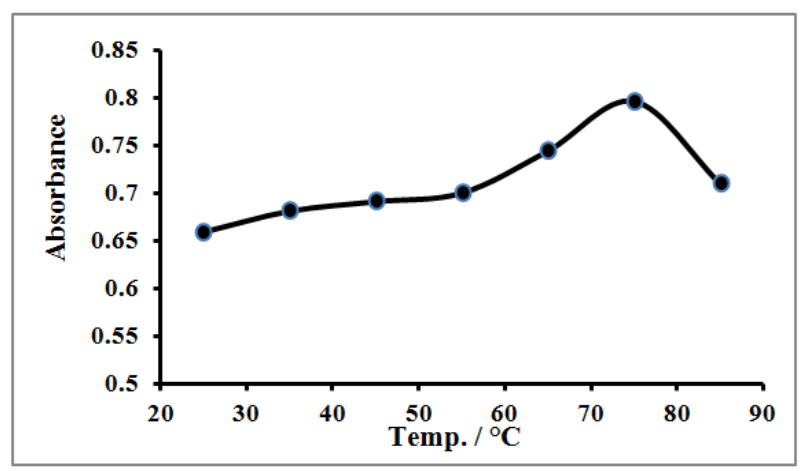

Figure 6. Effect of equilibration temperature on the CPE of Fe(III)-CIPRO complex

The effect of the incubation time was also carried out in the range of $5-40 \mathrm{~min}$ at $75^{\circ} \mathrm{C}$ (Figure 7). It was also noted that a
$25 \mathrm{~min}$ was adequate to achieve highest absorbance for the $\mathrm{Fe}$ (III)-CIPRO complex. The effect of centrifugation rate its time on the extraction efficiency of the complex was also studied and found that $6000 \mathrm{rpm}$ at $20 \mathrm{~min}$ was enough for the entire CPE.

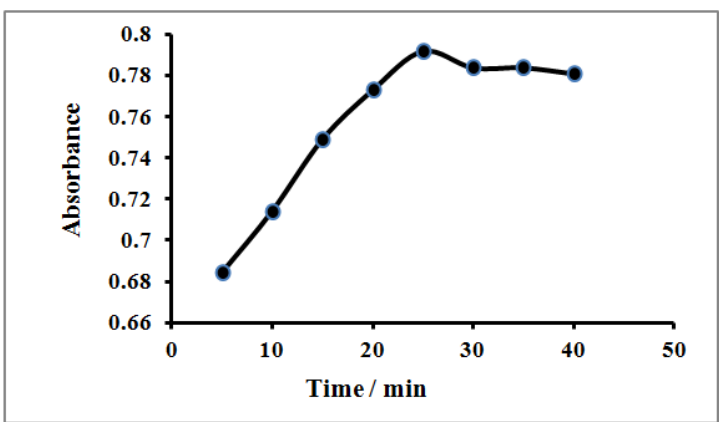

Figure 7. Effect of incubation time on the CPE of the Fe (III)-CIPRO complex.

\subsection{Stoichiometry of the Fe (III)-CIPRO Complex}

The determination of stoichiometry of Fe (III)-CIPRO complex was carried out by using mole ratio and Job plot of continuous variation methods. As previously mentioned, a deep yellow color is formed instantly when Fe(III) is added to ciprofloxacin in the presence of a wide concentration of sulphuric acid, indicative of complex formation. However, Figure 3 revealed that the optimum concentration of $\mathrm{H}_{2} \mathrm{SO}_{4}$ of $5 \times 10^{-4} \mathrm{M}$ was sufficient to form of the colored complex which appeared as shoulder peak extended to visible region with maximum absorbance at $437 \mathrm{~nm}$. Consequently, mole ratio and Job plot methods were used to assess the stoichiometry of Fe: CIPRO ratio at optimum concentration of sulphuric acid medium. The mole ratio method was performed at constant amount of Fe (III) with varying amount of CIPRO at optimum acid medium as shown in Figure 8.

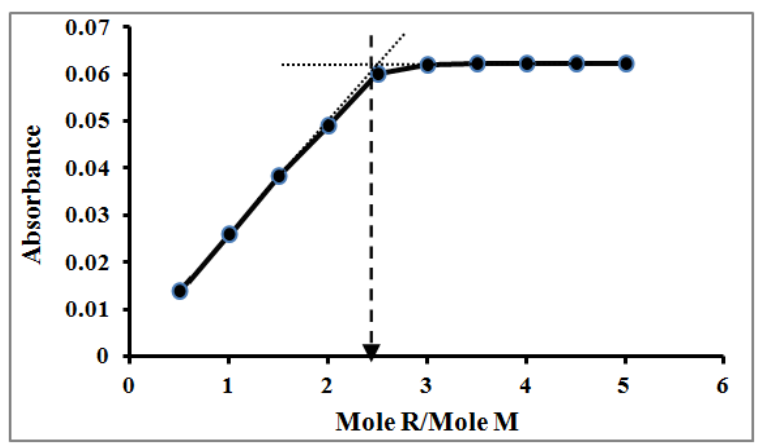

Figure 8. Mole ratio method for Fe (III)-CIPRO complex

It is obvious that the plotted curve exhibits a maximum mole ratio of $\mathrm{Fe}$ (III)-CIPRO complex via the point of intersection of the two lines which approach to 2.3 , indicating that the expected ratio Fe: CIPRO in the complex is $1: 2$. The Job plot was also confirmed similar result to molar ratio method which exhibits the mole fraction close to 0.50 , indicating again that the ratio of iron (III): drug in the complex is 1:2 as displayed in Figure 9. 


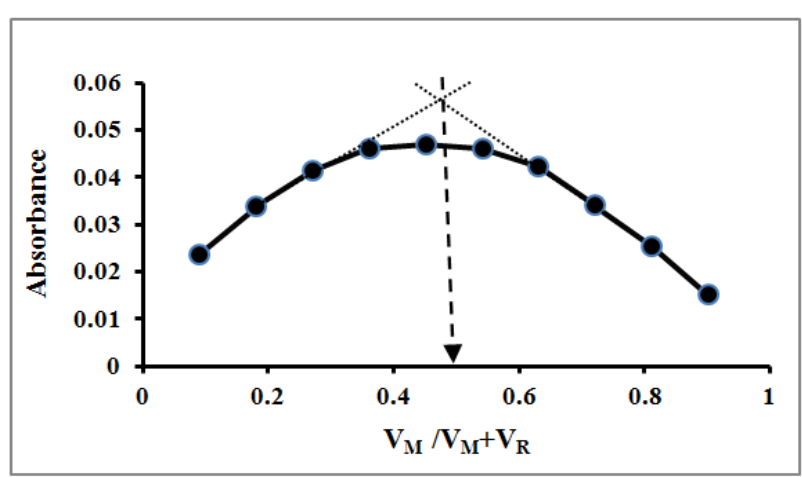

Figure 9. continuous variation methods for Fe (III) - CIPRO complex.

Our findings are in harmony with results obtained by Suliman and Sultan [41] and Al-Momani et al [43], but disagreed with the results published where a 1:1 complex was obtained, when iron (III) was complexed with ciprofloxacin at acidities higher than $0.025 \mathrm{M}$ [44]. The stability constant $\left(\mathrm{K}_{\mathrm{f}}\right)$ of the complex could be determined by using data from the molar ratio (Yoe-Jones plot ) or continuous variation method (Job's plot) by assuming that only single complex is present. The calculation was carried out according to the procedure adopted elsewhere [45]. The average stability constant $\left(\mathrm{K}_{\mathrm{f}}\right)$ of $\mathrm{Fe}$ (III)-CIPRO complex in both methods was of $5 \times 10^{11}$ at 437 $\mathrm{nm}$. This finding was higher than that obtained by Suliman and Sultan [41] who found that $\mathrm{K}_{\mathrm{f}}$ was of $5.7 \times 10^{7}$ at $447 \mathrm{~nm}$. Also, the standard free energy $\Delta \mathrm{G}^{\circ}$ for the complexation reaction of between $\mathrm{Fe}(\mathrm{III})$ ion and CIPRO was of a negative value and found to be of $(-18.63) \mathrm{kcal} \mathrm{mol}^{-1}$, indicating that the reaction is spontaneous. Hence, we can suggest that the possible structure of the complex formed between Fe (III) and CIPRO drug in acidic medium as displayed in Figure 10.

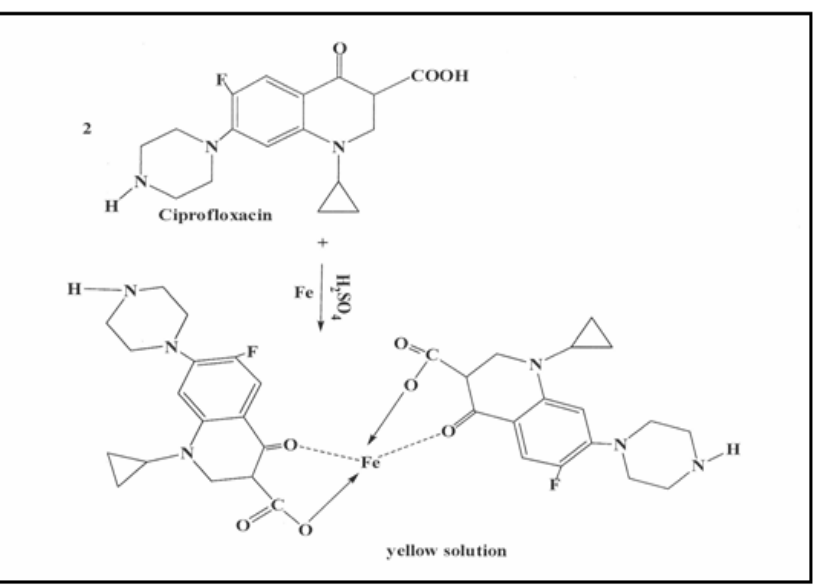

Figure 10. The probable structure of the complex formed between $\mathrm{Fe}$ (III) and CIPRO in acidic medium.

\subsection{Statistical Evaluation of Calibration Graph}

A series of standard of CIPRO solutions ranging from 2.5-120 $\mu \mathrm{g} \mathrm{mL}^{-1}$ were taken and subjected to the general CPE and the absorbance of each solution was measured at $\lambda_{\max }$ of $437 \mathrm{~nm}$, in order to construct the calibration curve, from which the CIPRO content was determined. The statistical data and other figures of merit are tabulated in Table 1.

The analysis of variance (ANOVA) of the regression line also demonstrated statistically valid, because the calculated F-value for 1 and 7 degree of freedom larger than critical values $\left(\mathrm{F}_{7}^{1}=5.59\right.$ at $95 \%$ C.I.), indicative the prediction based on the regression (9 points) is satisfactory [46] as presented in (Table 2).

Table 1. Statistical data and figures of merit of the proposed method for the determination of CIPRO at $\lambda_{\max }$ of $437 \mathrm{~nm}$.

\begin{tabular}{|c|c|}
\hline Parameter & value \\
\hline Regression equation & $y=0.01245 x-0.0332$ \\
\hline Std.dev. of regression line $\left(\mathrm{s}_{\mathrm{y} / \mathrm{x}}\right)$ & 0.00323 \\
\hline Correlation coefficient(r) & 0.9984 \\
\hline Coefficient of determination $\left(\mathrm{R}^{2}\right)$ & $99.69 \%$ \\
\hline C.L. for the slope $\left(\mathrm{b} \pm \mathrm{ts}_{\mathrm{b}}\right)$ at $95 \%$ & $0.01245 \pm 0.00061$ \\
\hline C.L. for the intercept $\left(\mathrm{a} \pm \mathrm{ts}_{\mathrm{a}}\right)$ at $95 \%$ & $0.0053 \pm 0.03857$ \\
\hline Concentration range $\left(\mu \mathrm{g} \mathrm{mL}^{-1}\right)$ & $2.5-120$ \\
\hline Limit of Detection $\left(\mu \mathrm{g} \mathrm{mL}^{-1}\right)$ & 0.77 \\
\hline Limit of Quantitation $\left(\mu \mathrm{g} \mathrm{mL}^{-1}\right)$ & 2.57 \\
\hline Preconcentration factor & 40 \\
\hline Enrichment factor & 143 \\
\hline $\begin{array}{l}\text { Sandell's sensitivity } \\
\left.\mu \mathrm{g} \mathrm{cm}^{-2} / 0.001 \mathrm{~A} . \mathrm{U}\right)\end{array}$ & 0.078 \\
\hline Molar absorptivity $\left(\mathrm{L} \cdot \mathrm{mol}^{-1} \cdot \mathrm{cm}^{-1}\right)$ & $1.0 \times 10^{4}$ \\
\hline Composition of complex (M: L) & $1: 2$ \\
\hline $\mathrm{RSD}^{2} \%(\mathrm{n}=7)$ at $80 \mu \mathrm{g} \mathrm{mL}^{-1}$ & 0.38 \\
\hline
\end{tabular}

Table 2. ANOVA test for regression line of CIPRO

\begin{tabular}{llllll}
\hline Source & DF & SS & MS & F & P \\
\hline Regression & 1 & 2.365958 & 2.365958 & 2256.776 & $4.79 \times 10^{-10}$ \\
Residual Error & 7 & 0.0007339 & 0.001048 & & \\
Total & 8 & 2.373297 & & & \\
\hline
\end{tabular}

$\mathrm{DF}=$ degrees of freedom, SS: sum of squares, MS: mean of squares, F (Fisher F-test), $\rho$ : probability.

The proposed method was achieved a wide linear concentration of $2.5-120 \mu \mathrm{g} \mathrm{mL} \mathrm{m}^{-1}$. Whilst the enrichment factor obtained was of 143 fold leading to achieve the limits of detection (LOD) of $0.77 \mu \mathrm{g} \mathrm{mL}^{-1}$ which almost in harmony with the results obtained by Desai et al [14] and Narayan et al [15] using HPLC technique. But, it was worse than obtained by Sarr et al [18], Zhang and Wei [6] whom used spectrofluorimetric and potentiometric techniques respectively. Also, the molar absorptivity, Sandell's sensitivity of complex formed was given in Table 1, indicative the proposed method has a good sensitivity.

\subsection{Accuracy and Precision}

Since the certificate reference materials (CRM's) for the determination of the CIPRO in serum sample is not available, accuracy has been tested through the percent recovery evaluation, in order to investigate if the proposed method is subjected to systematic error. Three serum samples were spiked with 15,20 and $25 \mu \mathrm{g} \mathrm{mL}^{-1}$ of CIPRO taking from the drug UFEXIL ${ }^{\circledR}$ infusion $\left(2000 \mu \mathrm{g} \mathrm{mL}^{-1}\right)$ solution produced by DEMO S.A. Pharmaceutical industry, which contains only lactic acid, sodium chloride, and water as additives. The Three spiked solutions were subjected to the recommended CPE procedure. The results were summed up in Table 3, indicated 
that the systematic errors insignificant in case of the presence of other constituents in serum and the drug matrices. Five replicate analyses of these three spiked solutions gave repeatability (\%RSD) between 0.08 and $0.68 \%$, indicative a good precision of the proposed method.

Table 3. The accuracy and precision

\begin{tabular}{|c|c|c|c|c|c|}
\hline CIPRO taken $\left(\mu \mathrm{g} \mathrm{mL}^{-1}\right)$ & CIPRO found $\left(\mu \mathrm{g} \mathrm{mL^{1 } )}\right.$ & Rec. $(\%)$ & $\mathrm{E}_{\mathrm{rel}}(\%)$ & Mean $\operatorname{Rec} \pm$ t.s $/ \sqrt{ }$ n at $95 \%$ CI & $\operatorname{RSD}(\%) n=5$ \\
\hline 15 & 14.878 & 99.18 & -0.81 & & 0.68 \\
\hline 20 & 19.800 & 99.00 & -1.00 & $98.89 \pm 0.87$ & 0.25 \\
\hline 25 & 24.626 & 98.50 & -1.49 & & 0.08 \\
\hline
\end{tabular}

\subsection{Determination of CIPRO in Serum Samples}

The proposed method was applied to the detection of CIPRO in blood serum samples for the volunteers whom orally administrated with a single tablet of Emicipro ${ }^{\circledR} 500$ containing $500 \mathrm{mg}$ of CIPRO as described in the experimental section. The results were presented in Table 4. Also, the proposed method was compared statistically with conventional spectrophotometric method and the paired t-test revealed that there is no significant difference at $95 \%$ confidence level, indicative the applicability and reliability of CPE-spectrophotometric methodology.

Table 4. Determination of CIPRO in human serums by proposed method compared statistically with traditional UV-Vis spectrophotometric method

\begin{tabular}{llll}
\hline Sample No. & Proposed method $\left(\boldsymbol{\mu g} \mathbf{~ m L}^{-1}\right)$ & direct $\mathbf{U V}$-Vis method $\left(\boldsymbol{\mu g} \mathbf{~ m L}^{-1}\right)$ & Paired t- test \\
\hline 1 & 55.43 & 54.62 & $\overline{\mathrm{X}}_{\mathrm{d}}=0.125$ \\
2 & 65.47 & 65.82 & $\mathrm{~S}_{\mathrm{d}}=0.500$ \\
3 & 70.77 & 70.70 & $\mathrm{t}_{\text {cal }(\mathrm{n}=10)}=0.790$ \\
4 & 42.34 & 42.03 & $\mathrm{t}_{\text {crit }}$ at $95 \mathrm{5} \% \mathrm{df} ; 4=2.26$ \\
5 & 82.76 & 81.10 & $\mathrm{P}-\mathrm{value}=0.686$ \\
6 & 84.63 & 83.97 & \\
7 & 37.46 & 37.41 & \\
8 & 53.52 & 54.20 & \\
10 & 98.74 & 98.71 & \\
\hline
\end{tabular}

The statistical analysis of the results shown in Table 4 reveals that the calculated experimental values $|\mathrm{t}|$ were 0.790 . This finding is less than the tabulated value of 2.26 at $95 \%$ confidence interval (dof $=9$, two-tailed), indicating that no significant difference between the proposed and conventional UV-Vis methods. We believe that the discrepancy in the amount of ciprofloxacin remaining and measured in the blood serum between volunteers as shown in
Table 4 may be due to the different amounts of drug absorbed from one person to another (i.e. depends on the nature of the metabolism between each volunteer) or to how discharge medication by the body; is that the remaining drug distracted by the kidneys? As it was, this is the reason that there is a difference in the proportion of drug in the blood because of the difference in kidney function among the volunteers.

\subsection{Determination of CIPRO in Pharmaceuticals}

Table 5. Determination of CIPRO in pharmaceutical formulations by proposed method and statistical comparison with quoted values.

\begin{tabular}{|c|c|c|c|c|}
\hline Drug & $\begin{array}{l}\text { Practical content (proposed* method })(\bar{x} \pm t s / \sqrt{ } n) \\
\text { at } 95 \% \text { C.I. }\end{array}$ & $\mathbf{t}=(\bar{x}-\mu) \sqrt{ } \mathbf{n} / \mathbf{s}$ Proposed method* with Quoted value at 95\%C.I. & $\mathbf{E}_{\text {rel }} \%$ & RSD\% \\
\hline \multirow{4}{*}{1} & 202.00 & \multirow[t]{2}{*}{$\mathrm{t}_{\mathrm{cal}}=0.221$} & \multirow[t]{4}{*}{0.36} & \multirow[t]{4}{*}{2.85} \\
\hline & 194.50 & & & \\
\hline & 205.75 & \multirow{2}{*}{$0.221<4.303$} & & \\
\hline & Ave: $200.73 \pm 14.23 \mathrm{mg} / 100 \mathrm{~mL}$ & & & \\
\hline \multirow{4}{*}{2} & 0.306 & \multirow[t]{2}{*}{$\mathrm{t}_{\mathrm{cal}}=2.76$} & \multirow[t]{4}{*}{1.86} & \multirow[t]{4}{*}{1.15} \\
\hline & 0.302 & & & \\
\hline & 0.309 & \multirow[t]{2}{*}{$2.76<4.303$} & & \\
\hline & Ave: $0.3056 \pm 0.009 \%$ & & & \\
\hline
\end{tabular}

$*(x)$ Mean of three determinations

(1)UFEXIL ${ }^{\circledR}$ infusion (DEMO S.A. Pharmaceutical industry, Greece) CIPRO (200 mg /100mL); (2) Ciprdar® eye drop (Dar Al Dawa,Na' ur-Jordan) CIPRO

The proposed method was also employed to the determination of CIPRO content in two selected pharmaceuticals containing CIPRO such as UFEXIL ${ }^{\circledR}$ (infusion) and Ciprodar $^{\circledR}$ (eye drop) with stated values of 200 $\mathrm{mg} / 100 \mathrm{~mL}$ and $0.3 \%$ respectively . The results are tabulated in Table 5. To validate the applicability of the proposed method, their results were compared statistically with quoted value claimed by manufacturing companies. As can be seen 
(Table 5) that the calculated t-values for both medicaments are less than the critical $(\mathrm{t}=4.303)$ at $95 \%$ confidence level and (n-1) degree of freedom, indicating the acceptance of manufacturer's claim $\left(\mathrm{Ho}=200\right.$ or $\left.\mathrm{H}_{\mathrm{o}}=0.3\right)$, so the null hypothesis $\mathrm{H}_{0}$ is maintained and concluding there is no evidence for systematic and random errors at the $95 \%$ confidence level.

\section{Conclusions}

In this work, a method was established for the determination of CIPRO in blood serum and pharmaceutical products by using combined CPE speectrophotometry, for the first time. The developed CPE- spectrophotometric method was characterized with simplicity, good sensitivity, and low detection limit and reliable for the determination of CIPRO. It proved to be accurate i.e. no significant difference between the experimental and quoted values claimed by manufactures, and it can be considered as an alternative to the other chromatographic separation techniques such as, HPLC, GC and electrophoresis.

\section{Acknowledgements}

The authors gratefully thank University of Baghdad/ College of Science for Women for the provision a grant to Noora Saad Mubdir for MSc study.

\section{References}

[1] The United States Pharmacopoeia 30 NF 25, US Pharmaceutical Convention, MD, e-book, 2007. pp. 1756

[2] H. Goossens, M. Ferech, S. Coenen, and P. Stephens, "Comparison of outpatient systemic antibacterial use in 2004 in the United States and 27 European countries," Clin. Infect. Dis. 44, pp.1091-1095,2007

[3] "British Columbia Annual Summary of Antibiotics Utilization 2010” BC Center for Disease Control, 2010, pp.72

[4] http://en.wikipedia.org/wiki/Ciprofloxacin.

[5] "Ciprofloxacin-Hydrochloride". The American Society of Health-System Pharmacists. Retrieved 3 April 2011

[6] S. Zhang, and S. Wei, "Electrochemical determination of Ciprofloxacin based on the enhancement effect of sodium dodecyl benzene sulfonate", Bull. Korean Chem. Soc., 28, pp. 543-546,2007

[7] B. Uslu, B. Bozal, and M.E. Kuscu, "Anodic voltammetry of ciprofloxacin and its analytical applications," The Open Chem. and Biomed. Methods J., 3, pp.108-114, 2010

[8] S.O. Thoppil, and P.D. Amin, "Stability indicating reversed-phase liquid chromatographic determination of ciprofloxacin as bulk drug and in pharmaceutical formulations," J. Pharm. Biomed. Anal. , 22, pp.699-703,2000

[9] S. Joshi, "HPLC separation of antibiotics present in formulated and unformulated samples," J. Pharm. Biomed. Anal., 28,pp. 795-809, 2002
[10] N.J. Kassab, A.K. Singh, E.R.M.K. Hackmam, and M.I.R.M. Santoro, " Quantitative determination of ciprofloxacin and norfloxacin in pharmaceutical preparations by high performance liquid chromatography," Brazilian J. Pharm. Sci. 41,pp.507-513,2005

[11] B.D. Witte, J. Dewulf, K. Demeestere, M.D. Ruyck, and H.V. Langenhove, "Critical points in the analysis of ciprofloxacin by high-performance liquid chromatography," J. Chromatogr. A, 1140, pp.126-130, 2007

[12] S.A.Ali, C.C. Mmuo, R.O. Abdulraheem, S.S. Abdulkareem, E.T. Alemika, A. Musa, M.A. Sani, and M. Ilya, "High performance liquid chromatography (HPLC) method development and validation indicating assay for ciprofloxacin hydrochloride,” J. Appl. Pharm. Sci., 01, pp. 239-243, 2011

[13] M.N. Qureshi, I.U. Rahman, and G. A. Marwat, "Comparative analysis of ciprofloxacin in different pharmaceutical products by high performance liquid chromatography," Sci., Tech. and Dev., 31, pp. 69-73,2012

[14] U.H. Desai, A.H. Patwari, J.K. Maradiya,M.K. Sathawara,B.N. Suhagia, and I.S. Rathod,"RP-HPLC method for simultaneous estimation of ciprofloxacin and dexamethasone in eye/ear drops," Int. J.Pharm. Sci. and Drug Res., 5, pp.62-66, 2013

[15] S.R.Narayan, S. Shisir, M. Umashankar, G. Bamakanta, S.S. Kumar, and H. Deepak, "Stability indicating RP-HPLC method development and validation of ciprofloxacin", Internatl. J. Pharm Chem. Sci., 3, pp.2014, 243-254,2014

[16] K. Torniainen, J. Mattinen, C.P. Askolin, and S. Tammilehto, "Structure elucidation of a photodegradation product of ciprofloxacin,” J. Pharm. Biomed. Anal. , 15, pp.887-894,1997

[17] K. Michalska, G. Pajchel, and S. Tyski, "Determination of ciprofloxacin and related impurities by capillary zone electrophoresis", J. Chromatogr. A. 1051, pp.267-272, 2004.

[18] S.O. Sarr, S.M.Ndiaye ,D. Fall , A. Diedhiou, A. Diop , B. Ndiaye , and Y.M. Diop, "Development and validation of a simple and economical spectrofluorimetric method for estimation of ciprofloxacin in pharmaceutical dosage forms," Int. J. Anal. and Bioanal. Chem., 3, pp.72-77,2013

[19] F.M. Abdel-Gawad, Y.M. Issa, H.M. Fahmy, H.M. Hussein," Spectrophotometric determination of ciprofloxacin in pure form and in tablets through charge-transfer complexation reactions," Mikrochim. Acta. , 130, pp. 35-40,1998

[20] M. Rizk, F. Balal, F. Ibrahim, S. Ahmed, and Z.A. Sheribah," Derivative spectrophotometric analysis of 4-quinolone antibacterials in formulations and spiked biological fluids by their $\mathrm{Cu}$ (II) complexes,” J. AOAC Int., 84,pp. 368-375,2001

[21] K. Basavaiah, P. Nagegowda, B. Chikkaswamy, and S.V. Ramakrishna," Spectrophotometric and titrimetric determinationof ciprofloxacin based on reactionwith cerium (IV) sulphate", ScienceAsia, 32, pp.403-409,2006

[22] G. Natesh, M.D. Azeez, M. Sabat, G. Venkatehwarl, N. Begum, and A. Srivani, "A new analytical method development and validation for estimation of ciproflaxacin and metronidazole by isoabsorption method by using UV - spectrophotometer," J. Chem. Bio. and Phys. Sci.,3, pp. 1663-1670,2013

[23] B. PavaniPadmaPriya, "new spectrophotometric multicomponent estimation of ciprofloxacin and tinidazole tablets", Int. J. ChemTech Res., 5, pp. 42-46,2013 
[24] F. Vallée, M. Lebel, and M.G. Bergeron,"Determination of ciprofloxacin in biological samples by reversed-phase high performance liquid chromatography," Ther Drug Monit. , 8,pp. $340-345,1986$

[25] S. Eposito, D. Galante, D. Barba, G. D'errico, and A. Mazzone, "Ciprofloxacin concentrations in human fluids and tissues following a single oral dose," J. Clin. Pharmacol. Res., 7,pp. $181-186,1987$

[26] M. Lovdahl, J. Steury, H. Russlie, and D.M. Canafax, " Determination of ciprofloxacin levels in chinchilla middle ear effusion and plasma by high performance liquid chromatography with fluorescence detection," J. Chromatogr. , 617, pp.329-333,1993

[27] K. Kamberi, K.T. Tsutsmi, T. Kotegawa, K. Nakamura, and S. Nakano, "Determination of ciprofloxacin in plasma and urine by HPLC with ultraviolet detection," Clinical Chemistry, 44, pp.1251-1255,1998

[28] A. Dincel, A. Yildirim, F. Caglayan, and A. Bozkurt, "Determination of Ciprofloxacin in Human Gingival Crevicular Fluid by High Performance Liquid Chromatography," Acta Chromatographica, 15,pp.308-314, 2005

[29] D.G. Gomez, A. Espinosa-Mansilla, A.M. de la Pena, and F.C. Canada, "HPLC determination of ciprofloxacin, cloxacillin and ibuprofen drugs in human urine samples," J. Pharm. Sci., 29, pp.1969-1976,2006

[30] M.A. Ibrahim, H.Y. Aboul-Enein, E.M. Niazy ,K.I. Alkhamis, and K.A. Alrashood, "High performance liquid chromatographic assay of ciprofloxacin in human plasma using fluorescence detection," Gazi University Journal of Science GU J Sci., 26, pp. 31-37,2013

[31] Z.A-A. Khammas, A.A. Ghali, K.H. Kadhim, "Combined cloud-Point extraction and spectrophotometric detection of lead and cadmium in honey samples using a new ligand,".Int. J. Chem. Sci.: 10, pp.1185-1204, 2012

[32] Z.A-A. Khammas, S.K. Jawad, and I.R. Ali, “ A new approach for extraction and determination of manganese in environmental samples using cloud-point extraction coupled with spectrophotometry," Chem. Sci. Trans., 3, pp. 255-267, 2014

[33] Z.A-A. Khammas, Z. S.K. Jawad, S.K. and I.R. Ali, “ A new spectrophotometric determination of chromium (VI) as $\mathrm{Cr}_{2} \mathrm{O}_{7}{ }^{2-}$ after cloud-point extraction using a laboratory made organic reagent, " Global Journal of Science Frontier Research Chemistry, 13 (8) Version 1.0, 2013, 9-19,2013

[34] Z. A-A. Khammas, "Recent trends for separation and preconcentration in metal ions and organic compounds analysis after clould-point methodology: developments and analytical applications - A review", Eurasian J. Anal. Chem. 4(1),pp. $1-35,2009$
[35] A. Ohashi, M. Ogiwara, R. Ikeda, H. Okada, and K. Ohashi, "Cloud point extraction and preconcentration for the gas chromatography of phenothiazine tranquilizers in spiked human serum, “Anal Sci. 20(9), pp. 1353-1357, 2004.

[36] A.B. Tabrizi, "A cloud point extraction-spectrofluorimetric method for determination of thiamine in urine", Bull. Korean Chem. Soc., 27, pp. 1604-1608, 2006

[37] C.C.Wang, M.O.Luconi, A.N. Masi, and L. Fernández," Determination of terazosin by cloud point extraction-fluorimetric combined methodology," Talanta ,72, pp. 1779-1785, 2007

[38] H. Zhang, and H.K. Choi, "Analysis of meloxicam by high-performance liquid chromatography with cloud-point extraction,” Anal Bioanal Chem., 392, pp.947-953,2008

[39] H. Wu, G.Y. Zhao, and L.M. Du, "Determination of ofloxacin and gatifloxacin by mixed micelle-mediated cloud point extraction-fluorimetry combined methodology," Spectrochim Acta A: Mol Biomol Spectrosc.,75, pp.1624-1628, 2010

[40] M. Nawaz, "Simultaneous determination of non-steroidal anti-inflammatory drugs in pharmaceutical formulations and human serum by reversed phase high performance liquid chromatography,” Quim. Nova,35, pp. 939-943, 2012

[41] F.E.O.Suliman, and S.M. Sultan,"Sequential injection technique employed for stoichiometric studies, optimization and quantitative determination of some fluoroquinolone antibiotics complexed with iron(II1) in sulfuric acid media," Talanta, 43,pp. 559-568,1996

[42] S. Wifky, T.A. El-Naggar, E.A. Lasheen, and A.K.G.Nouh,"Cloud point extraction and preconcentration of gold in geological matrices prior to flame atomic absorption determination,” Cent. Eur. J. Chem., 8, pp.34-40,2010

[43] F. Idrees, A.T.H. Al-Momani, and A.N. Tahtamouni, "Flow injection spectrophotometric and chromatographic determination of ciprofloxacin and norfloxacin in pharmaceutical formulations," J. Flow Injection Anal., 25, pp.151-155, 2008

[44] S.M.Sultan and F.O. Suliman, "Flow injection spectrophotometric determination of the antibiotic ciprofloxacin in drug formulations," Analyst, 117, pp.1523-1526, 1992

[45] S. Brewer, "Solving problems in analytical chemistry," John Wiley and Sons, USA, 1980, pp289-299.

[46] W.P. Gardiner, "Statistical analysis methods for Chemists: A software-based approach," the Royal Society Chemistry, Thomas Graham House, Cambridge, UK, Chapter 5, 1997,pp.168. 